\title{
Meta-Analysis of Food Effect on Oral Absorption of Efflux Transporter Substrate Drugs: Does Delayed Gastric Emptying Influence Drug Transport Kinetics?
}

\author{
Sheena Sharma and Bhagwat Prasad * \\ Department of Pharmaceutical Sciences, Washington State University, 412 E Spokane Falls Blvd, \\ Spokane, WA 99202, USA; sheena.sharma@wsu.edu \\ * Correspondence: bhagwat.prasad@wsu.edu; Tel.: +1-(509)-358-7739; Fax: +1-509-368-6561
}

Citation: Sharma, S.; Prasad, B. Meta-Analysis of Food Effect on Oral Absorption of Efflux Transporter Substrate Drugs: Does Delayed Gastric Emptying Influence Drug Transport Kinetics? Pharmaceutics 2021, 13, 1035. https://doi.org/ 10.3390/pharmaceutics13071035

Academic Editor: Gert Fricker

Received: 16 June 2021

Accepted: 4 July 2021

Published: 7 July 2021

Publisher's Note: MDPI stays neutral with regard to jurisdictional claims in published maps and institutional affiliations.

Copyright: (c) 2021 by the authors. Licensee MDPI, Basel, Switzerland. This article is an open access article distributed under the terms and conditions of the Creative Commons Attribution (CC BY) license (https:// creativecommons.org/licenses/by/ $4.0 /)$.
Abstract: The oral route of drug administration is the most convenient method of drug delivery, but it is associated with variable bioavailability. Food is one of the major factors that affect oral drug absorption by influencing drug properties (e.g., solubility and dissolution rate) and physiological factors (e.g., metabolism and transport across the gastrointestinal tract). The aim of this work was to investigate the effect of food on the high-affinity intestinal efflux transporter substrate drugs. We hypothesized that transport efficiency is higher in the fed state as compared to the fasted state because of the lower intestinal lumen drug concentration due to prolonged gastric emptying time. A systematic analysis of reported clinical food-effect (FE) studies on 311 drugs was performed and the association of the efflux transport efficiency was investigated on the FE magnitude, i.e., changes in maximal plasma concentration and area under the plasma concentration-time profile curve for both solubility and permeability-limited drugs. In total, 124 and 88 drugs showed positive and negative FE, respectively, whereas 99 showed no FE. As expected, the solubility-limited drugs showed positive FE, but interestingly, drugs with a high potential for efflux transport, were associated with negative FE. Moreover, a high-fat diet was associated with a higher magnitude of negative FE for high-affinity efflux transporter substrates as compared to a low-fat diet. To account for changes in drug absorption after food intake, the prolonged gastric emptying time should be considered in the physiologically based pharmacokinetic (PBPK) modeling of orally absorbed efflux transporter substrate drugs.

Keywords: oral absorption; food-effect prediction; intestinal transporter; efflux transport; P-gP; BCRP

\section{Introduction}

Although $85 \%$ of the top 200 prescription drugs are administered orally [1], high variability in oral drug pharmacokinetics $(\mathrm{PK})$ is associated with a risk of toxicity or lack of efficacy for narrow-therapeutic index drugs [2]. Oral drug absorption is influenced by multiple extrinsic and intrinsic factors that can alter systemic drug exposure $[3,4]$. Food is one of the major extrinsic factors that affects the absorption of oral drugs including narrow therapeutic index drugs such as amiodarone [5], phenytoin [6], rifampicin [7], and tacrolimus [8]. Food can influence several drug properties, including dissolution rate, ionization state, complexation, and chemical stability [2]. More importantly, food intake is associated with physiological factors such as prolonged gastric emptying time (GET) [9], increased luminal viscosity [10], increased $\mathrm{pH}$ and luminal fluid volume [11], shorter gallbladder emptying time [12,13], increased bile acid secretion [12,14], increased splanchnic blood flow (i.e., blood draining stomach, intestine, spleen, and pancreas) [15,16], and altered drug-metabolizing enzyme and transporter (DMET) activity [17]. However, the impact of the complex interplay of altered drug properties and physiological factors on drug absorption in the fed versus the fasted state is not well characterized.

The food and drug administration (FDA) recommends food-effect (FE) bioavailability and fed bioequivalence studies prior to regulatory approval of a new or abbreviated new 
drug application $[18,19]$. Although drug safety profiles are evaluated in the fasted state during clinical trials, FE prediction is required for the first-in-human fed state trials. The current practices of FE assessment during drug development typically involve dissolution studies in the fed state simulated gastric or intestinal media [20]. In general, food can influence dissolution and/or permeability. The dissolution rate can be influenced by bile salt-mediated micellar formation that can affect the type and magnitude of FE, which is predictable by in vitro dissolution tests [21]. Five-fold higher bile acid concentration in the fed state facilitates the solubilization of solubility-limited drugs through micelle formation [14].

As per the FDA, a positive or negative FE is clinically significant if the $90 \%$ confidence interval for the ratio of population geometric means of the maximum concentration $\left(\mathrm{C}_{\max }\right)$ or the area under the plasma concentration-time profile curve (AUC) in the fed state is above $125 \%$ or below $80 \%$ as compared to the fasted state. The known mechanisms of positive FE include increased bile salt-mediated solubilization [5,22], decreased firstpass metabolism due to increased splanchnic blood flow [23], and inhibition of efflux transporters [24,25] and intestinal metabolism [26,27]. In contrast, the mechanisms of negative FE include drug adsorption on food-component or bile salts [28,29], inhibition of uptake transporters [30], increased viscosity [10,31], and increased gastric $\mathrm{pH}$ [32]. These effects can be studied through in vitro models, utilizing dissolution studies to successfully predict the effect of $\mathrm{pH}$ and bile acid solubilization, and using transporter-expressing cells or vesicles to investigate the transporter inhibition [33,34]. However, physiological changes such as prolonged GET, and increased blood and bile flow cannot be simulated in dissolution studies, which is often the cause of disconnect between in vitro and in vivo data $[21,35,36]$. For example, the dissolution study of a breast cancer resistant protein (BCRP) substrate, furosemide, in simulated gastric fluid showed $\sim 70$-fold higher solubility in the fed versus fasted state [35], contrary to a $45 \%$ decrease in the AUC in the fed state in humans [37] (Figure 1). Considering the clinical implications of FE, it is crucial to develop a deeper understanding of the plausible mechanisms of such complex food-drug interactions.

(A)

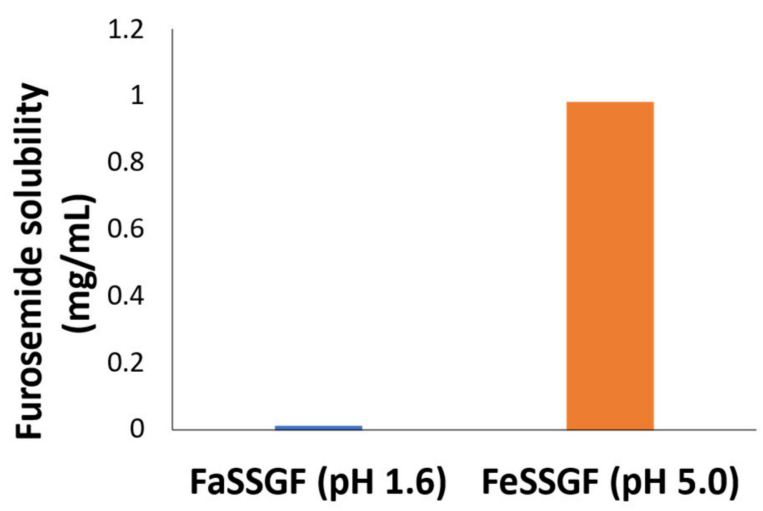

(B)

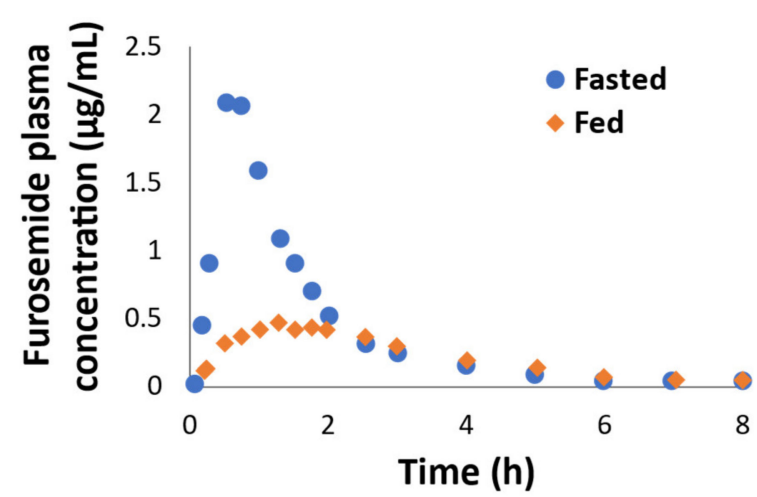

Figure 1. In vitro-in vivo relationship disconnect between in vitro solubility (A) and clinical food-effect data in furosemide (B). The $42 \%$ decreased AUC in fed versus fasted state is not explained by furosemide solubility data, which shows a 70-fold higher solubility in the fed state ( $\mathrm{pH}$ 5.0) compared to fasted state ( $\mathrm{pH} 1.6)$ in simulated gastric fluid (FeSSGF and FaSSGF, respectively).

To explain negative FE on the high-affinity efflux transporter substrates, we hypothesized that prolonged gastric emptying in the fed state results in decreased drug concentration in the intestinal lumen, which increases the transport efficiency in the fed state as compared to the fasted state. To test this, we analyzed 311 drugs with reported clinical FE studies to assess the effect of food on oral absorption of high-affinity efflux transporter substrates. 


\section{Materials and Methods}

2.1. Collection of Physicochemical, Biochemical, and Plasma Concentration Data for Drugs with Reported Clinical Food-Effect Studies

A systematic literature search was conducted according to the guidelines outlined by Preferred Reporting Items for Systematic Reviews and Meta-Analysis (PRISMA) on drugs with reported clinical FE studies ( $n=311$ drugs) published prior to August 2020 through online search engines, i.e., PubMed, Google Scholar, and ScienceDirect (Figure 2), using the following keywords: Food and bioavailability, food and clinical pharmacokinetics, and food and drug absorption. Only human studies were included and, when more than one study was reported, the study with the greatest change in the PK parameters was considered. The $\mathrm{C}_{\max }, \mathrm{AUC}$, and the type of meal were compiled (Supplementary Table S1). An average American diet with a high-fat content was considered to represent the worst-case scenario.

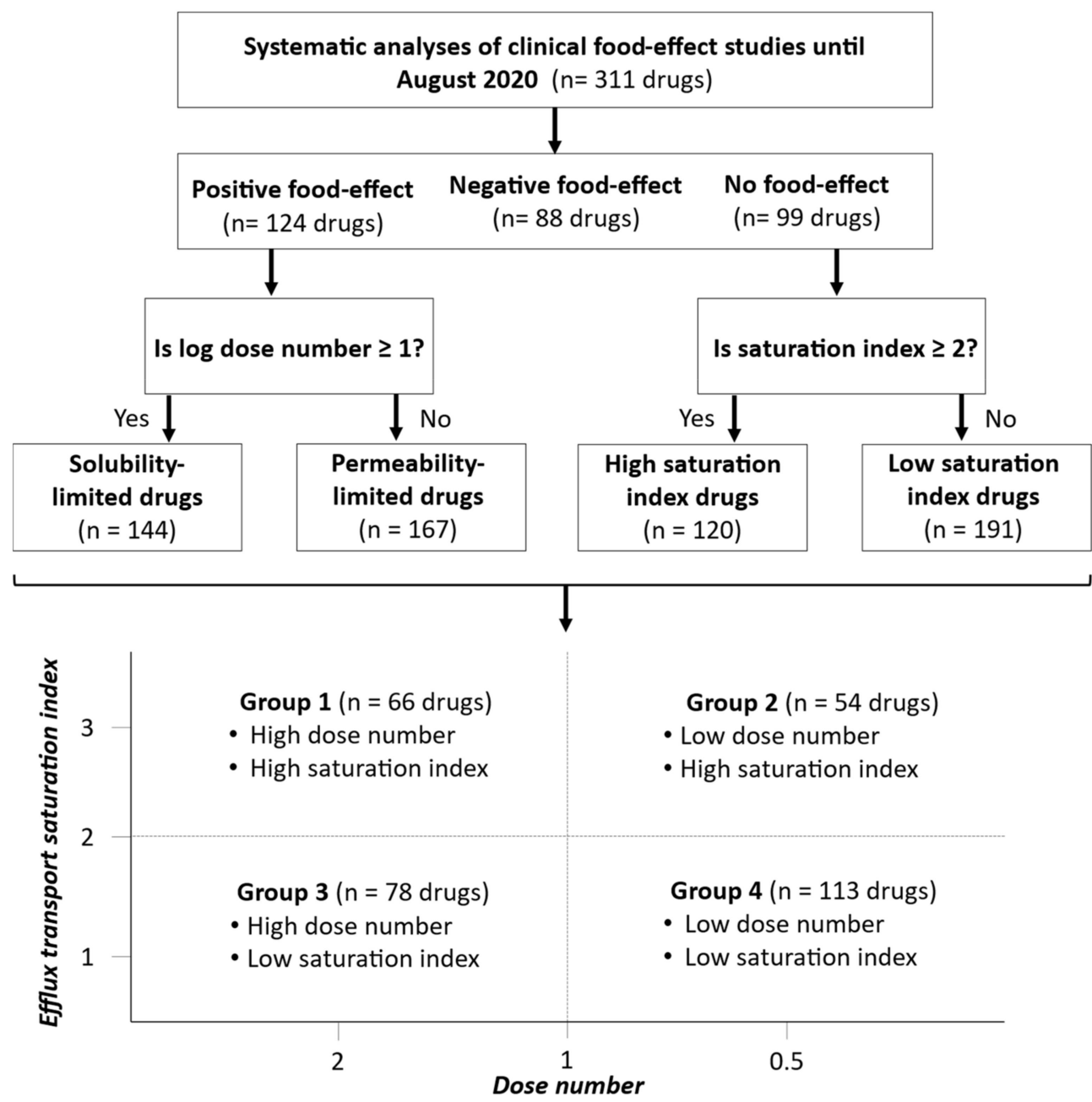

Figure 2. Workflow of systematic analysis of 311 drugs followed by segregation of drugs in four groups based on dose number and efflux transport saturation index. Dose number and efflux transport saturation indices were calculated based on Equations (2) and (3), respectively. Groups 1 and 3 are solubility-limited (log dose number $\geq 1$ ), and groups 2 and 4 are permeability-limited (log dose number $<1$ ).

The observed FE on drug PK parameters was calculated using Equation (1).

$$
\text { Change in } \mathrm{C}_{\max } \text { or AUC }(\%)=\frac{\text { Fed }_{\mathrm{C}_{\max }} \text { or AUC }- \text { Fasted }_{\mathrm{C}_{\max }} \text { or AUC }}{\text { Fasted }_{\mathrm{C}_{\max }} \text { or AUC }} \times 100
$$




\subsection{Identification of Solubility-and Permeability-Limited Drugs}

Food increases the absorption of solubility-limited drugs by increasing bile micellar solubilization $[5,22]$. The drugs with a log dose number $\geq 1$ were assumed to be solubilitylimited. The dose number was calculated from drug solubility data and the respective dose strengths (Equation (2)) where the dose strength is the administered dose (mg), the volume is the total water intake (assumed $250 \mathrm{~mL}$ ), and the solubility is in $\mathrm{mg} / \mathrm{mL}$ [38].

$$
\text { Dose number }=\frac{\frac{\text { Dose strenght }}{\text { Volume }}}{\text { Solubility }}
$$

\subsection{Stratification of Drugs Based on Transport Saturation Index}

High-affinity transporter substrate drugs (low Michaelis-Menten constant, $\mathrm{K}_{\mathrm{m}}$ ) are prone to exhibit saturable transporter kinetics. Since the fed state delays GET from $15 \mathrm{~min}$ to $2 \mathrm{~h}$, it is important to identify the efflux transporter substrate drugs that could likely exhibit saturable kinetics in the fasted state (shorter GET). To do so, we first determined the efficiency of efflux transport by utilizing the "saturation index" (Equation (3)), a new term, where the active transport was assumed saturable when the estimated luminal drug concentration was two-fold higher than the $\mathrm{K}_{\mathrm{m}}$. The luminal drug concentration was estimated based on the administered dose strength dissolved in a typical dosing liquid volume, i.e., $250 \mathrm{~mL}$ [38]. If the $\mathrm{K}_{\mathrm{m}}$ value for efflux transport was not reported, it was assumed $100 \mu \mathrm{M}$ ( low-affinity) to account for the worst-case scenario.

$$
\text { Saturation index }=\frac{\text { Luminal drug concentration }}{\mathrm{K}_{\mathrm{m}}}
$$

\subsection{Effect of Efflux Transport Saturation on Food-Effect for Permeability-Limited Drugs}

The association of FE magnitude ( $\mathrm{C}_{\max }$ and AUC changes) was assessed with the $\log$ dose number and efflux transport saturation index for the studied drugs $(\mathrm{n}=311)$. The drugs were stratified into four groups based on the respective thresholds of the log dose number $(\geq 1$ or $<1)$ and the efflux transport saturation index $(\geq 2$ or $<2)$. First, the frequency of specific FE was evaluated within each group. Then, the FE magnitude on $\mathrm{C}_{\max }$ and AUC across four groups was analyzed using Kruskal-Wallis followed by Dunn's multiple comparison tests using GraphPad Prism v. 8.4.3. software (San Diego, CA, USA) and RStudio version 1.2.1335 (Boston, MA, USA).

\subsection{Impact of High-versus Low-Fat Diets on Drug Absorption}

$\mathrm{C}_{\max }$ and AUC of the drugs studied for FE in both high- and low-fat diets were compiled. The impact of diet on FE magnitude of high-affinity efflux transporter substrates was compared by the paired t-test.

\section{Results}

\subsection{Stratification of Drugs Based on the Food-Effect Magnitude}

Out of 311 studied drugs, 124 and 88 drugs were reported to have a positive and negative FE on drug absorption, respectively, whereas 99 drugs showed no FE (Supplementary Table S1). These drugs were stratified based on log dose number and efflux transport saturation indices into four groups as shown in Figure 2, i.e., (i) group 1: Log dose number $\geq 1$ and efflux saturation index $\geq 2$ ( $\mathrm{n}=66$ drugs); (ii) group 2: Log dose number $<1$ and efflux saturation index $\geq 2$ ( $\mathrm{n}=54$ drugs); (iii) group 3: Log dose number $\geq 1$ and efflux saturation index $<2$ ( $\mathrm{n}=78$ drugs); and iv) group 4: Log dose number $<1$ and efflux saturation index $<2$ ( $\mathrm{n}=113$ drugs). 
Association of Efflux Transport Saturation on Food-Effect for Solubility- and Permeability-Limited Drugs

The drugs in groups 1 and 3 represent the solubility-limited drugs (log dose number $\geq 1$ ), which, as expected, showed a higher likelihood of positive FE. The drugs in groups 2 and 4 were permeability-limited drugs (log dose number $<1$ ), which showed a higher likelihood of having a negative or no FE (Figure 3A). In particular, significant differences $(p<0.05)$ in $C_{\max }$ and AUC (median, \%) were observed between groups 1 vs. 2, 1 vs. 3,2 vs. 3 , and 3 vs. 4, as determined by Kruskal-Wallis followed by Dunn's multiple comparison tests (Figure 3B,C and Table 1). The highest magnitude of positive FE was observed in group 3 followed by groups 1, 4 and 2, respectively, as reflected by corresponding percent changes in $C_{\max }(44.5>18>8.8>-21.9)$, and AUC $(42.4>14.8>7.8>-1.2)$ (Figure 3B,C, Table 1). Consistent with our novel hypothesis, group 2 showed the highest magnitude of negative FE, calculated as $\mathrm{C}_{\max }$ (median, $-21.9 \%$ ) and AUC (median, $-1.2 \%$ ) changes (Table 1). Asciminib, 5-fluorouracil, voriconazole, furosemide, and theophylline, are some of the high-affinity efflux transporter substrates (group 2) that show negative FE. $\mathrm{FE}$ is found to have a more pronounced effect on $C_{\max }$ than AUC indicating the effect of fed state on drug absorption phase.

(A)

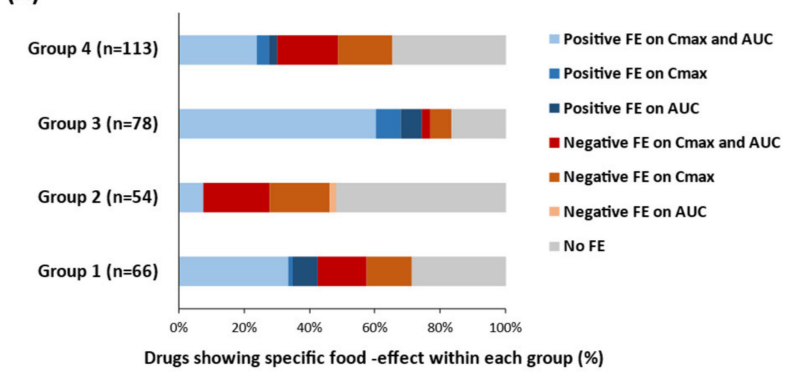

(B)

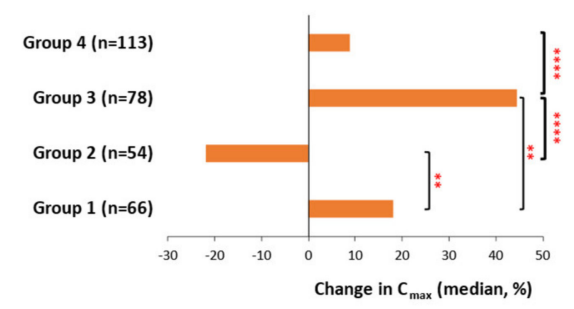

(c)

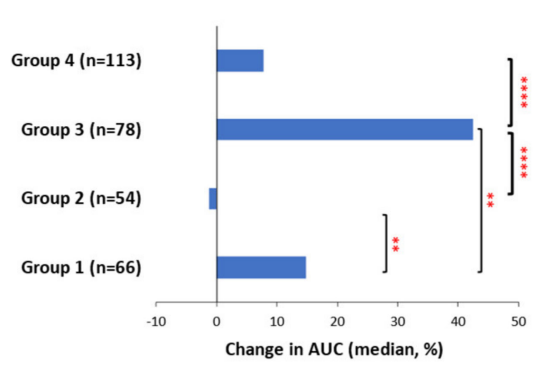

Figure 3. The association of solubility- and permeability-limited groups (1-4) with change in the PK endpoints ( $C_{\max }$ and AUC). (A) Qualitative evaluation of each group to assess the frequency of drugs showing positive, negative, or no food-effect. (B) Changes in $\mathrm{C}_{\max }(\%$, median) across each group. (C) Changes in AUC (\%, median) across the four groups. Kruskal-Wallis followed by Dunn's multiple comparison tests showed a significant difference in $\mathrm{C}_{\max }(\mathbf{B})$ and AUC (C) between groups 1 vs. $2\left(^{* *} p<0.01\right), 1$ vs. $3\left(^{* *} p<0.01\right), 2$ vs. $3\left(^{* * * *} p<0.0001\right)$, and 3 vs. $4\left(^{* * * *} p<0.0001\right)$. The difference in AUC or $C_{\max }$ between all other group pairings was non-significant. 
Table 1. Comparison of food-effect magnitude (change in $\mathrm{C}_{\max }$ and AUC) across different groups.

\begin{tabular}{|c|c|c|c|c|c|c|}
\hline \multirow{2}{*}{ Groups } & \multicolumn{3}{|c|}{$\mathrm{C}_{\max }$ Change (\%) * } & \multicolumn{3}{|c|}{ AUC Change (\%) * } \\
\hline & Mean & Median & $95 \% \mathrm{CI}^{\ddagger}$ & Mean & Median & $95 \% \mathrm{CI}^{\ddagger}$ \\
\hline Group 1 & 69.5 & 18 & {$[-21.6,48.1]$} & 82.1 & 14.8 & {$[3.9,39.9]$} \\
\hline Group 2 & $-15.4^{\neq}$ & $-21.9^{\neq \neq}$ & {$[-28,10.4]$} & $-7.4^{\neq}$ & $-1.2^{\neq}$ & {$[-16.1,8.2]$} \\
\hline Group 3 & 619 & 44.5 & {$[25.8,84]$} & 482.4 & 42.4 & {$[25,87]$} \\
\hline Group 4 & 9.2 & 8.8 & {$[-25,19.3]$} & 23.5 & 7.8 & {$[-2,12.5]$} \\
\hline
\end{tabular}

${ }^{*} \mathrm{C}_{\max }$ and AUC change values were estimated using Equation (1); ${ }^{\neq \neq} 95 \% \mathrm{CI}, 95 \%$ confidence interval across median; ${ }^{* \neq}$ Negative sign indicates negative food-effect.

\subsection{Impact of High-Fat versus Low-Fat Diets on Drug Absorption}

Drugs with high-affinity efflux transport showed greater negative FE with a high-fat diet as compared to with a low-fat diet. These data also corroborate our hypothesis because a high-fat diet further delays GET. For example, omadacycline, eltrombopag, indinavir, and asciminib showed significantly decreased $C_{\max }(p<0.01)$ and AUC $(p<0.001)$ after the high-fat diet as compared to the low-fat diet (Figure 4).
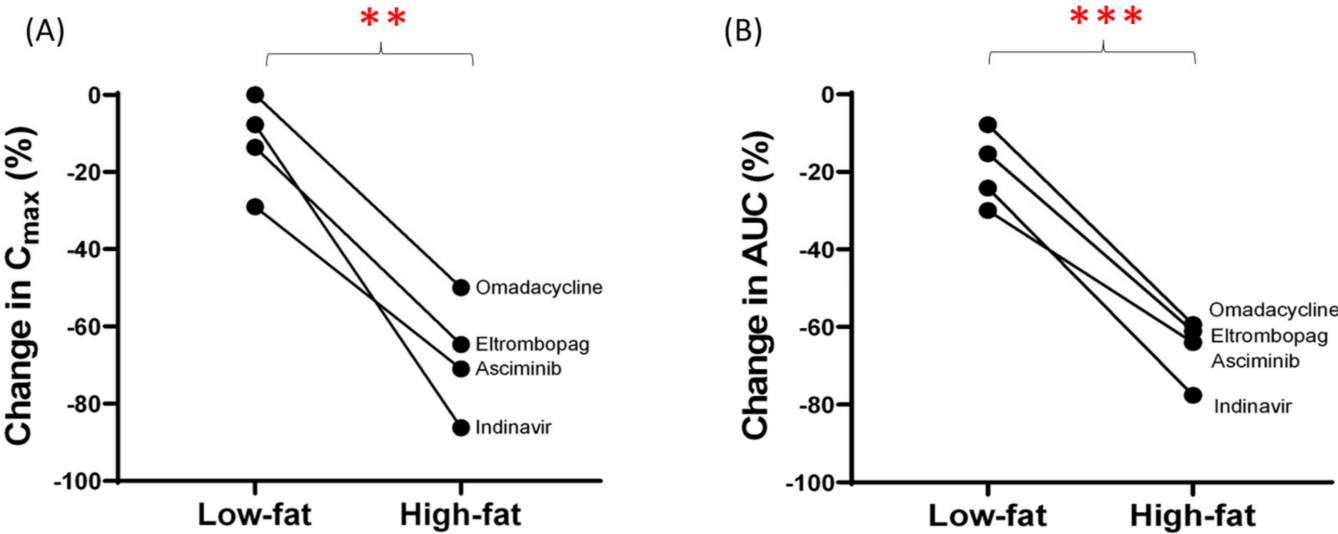

Figure 4. The association of diet-type on the magnitude of negative food-effect. The change in $C_{\max }(\mathbf{A})$ and AUC (B) were compared for the high-affinity efflux transporter substrates, i.e., omadacycline, eltrombopag, indinavir, and asciminib, with known food-effect data following a high- and low-fat diet. The longer gastric emptying time caused by the high-fat diet is a likely mechanism of the increased efficiency of efflux transport. ${ }^{* *}$ and ${ }^{* * *}$ indicate $p<0.01$ and $p<0.001$, respectively (paired $t$-test)

\section{Discussion}

The effect of food on drug absorption is one of the major causes of inter-individual variability in drug bioavailability $[39,40]$. Prospective prediction of FE is important for clinical trial design and dosing regimen prediction, particularly for narrow-therapeutic index drugs. In drug development, FE studies are generally conducted during the Phase II clinical trials. The potential for FE is conventionally tested based on the fed state simulated dissolution data $[18,19]$. However, the dissolution testing could fail to predict FE because of the complex interaction between food and gastrointestinal physiology. In particular, the interplay of efflux transporters and prolonged GET in the fed state is not well characterized.

Our data confirmed that solubility-limited drugs have a higher likelihood of positive FE, which is explained by increased solubilization due to higher bile acid secretion in the fed state as observed in the case of testosterone undecanoate [22] and amiodarone [5]. More importantly, our data analysis suggests that food associated prolonged GET affects the efficiency of apical efflux transporters in the fed state due to lower luminal drug concentrations. For example, efflux transporter substrate drugs such as asciminib [41], 5-fluorouracil [42], voriconazole [43], furosemide [37], and theophylline [44] showed nega- 
tive FE. This observation can be explained by the altered transport kinetics phenomenon illustrated in Figure 5. To further support our hypothesis, we observed a higher magnitude of negative FE in the high-fat diet as compared to the low-fat diet conditions (Figure 4). Typically, a high fat diet is associated with an increased bile-micelle solubilization, which is likely a mechanism of a positive FE; however, it is contrary to our observation (Figure 4). Therefore, the negative FE in efflux transporter substrate drugs such as omadacycline, eltrombopag, indinavir and asciminib is likely due to the increased net efficiency of apical efflux transport caused by greater GET in the fed state following a high-fat meal [9]. While a high fat diet has been shown to be associated with an increased mRNA expression of Bcrp in mice [45] due to the lag time in the mRNA and protein synthesis, it is unlikely that Bcrp induction causes any clinically significant effects on the absorption phase (1-2 h) of drugs.

(A)

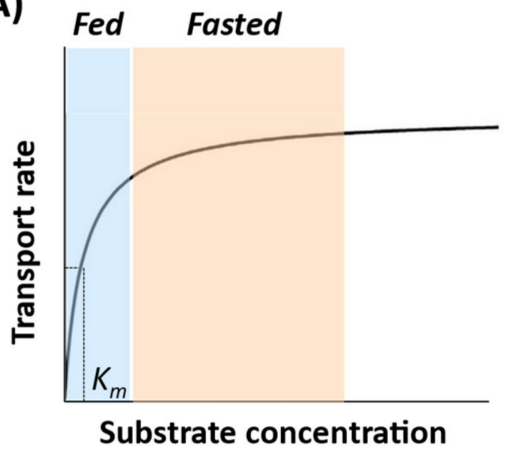

(B)

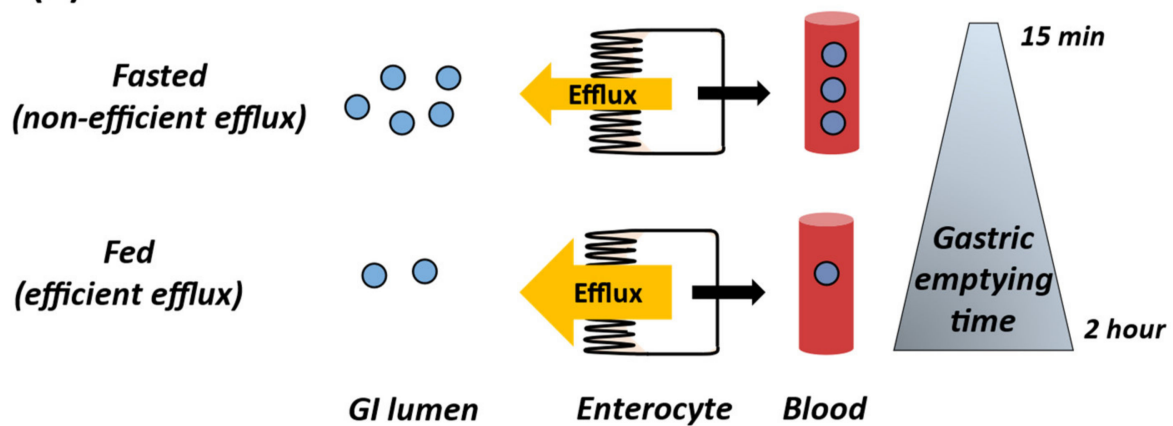

Figure 5. Proposed mechanisms of complex interplay of efflux transport and food-effect on drug absorption. (A) The phenomenon of higher efficiency of efflux transport in the fed state can be visualized by making an analogy to the classical Michaelis-Menten curve, i.e., the drug follows a linear range of transport velocity in the fed state due to the prolonged gastric emptying time (lower substrate concentration) as compared to the saturable transport in the fasted state. (B) The shorter gastric emptying time in the fasted state leads to a higher drug concentration relative to the Michaelis-Menten constant $\left(\mathrm{K}_{\mathrm{m}}\right)$. Whereas, prolonged gastric emptying time in the fed state leads to the increased efficiency of efflux transporters, resulting in a negative food-effect for efflux transporter substrate drugs. The efficiency of transport can be defined as a ratio of the rate of transport and substrate concentration, which gets increased in the fed state as compared to the fasted state.

Our hypothesis is supported by a few reported anecdotal data. For example, consistent with our observation, Yamamoto et al. demonstrated the interplay of food and P-gp on the oral drug absorption of an investigational compound (T-3256336) in rats [46]. T-3256336 showed a three-fold lower AUC in the fed state than the fasted state (Supplementary Figure S1). However, no FE was observed when T-3256336 was coadministered with a selective P-gp inhibitor (elacridar). This suggests a P-gp dependent FE for T-3256336 that can be explained by the higher efficiency of P-gp efflux in the fed state due prolonged GET. Similarly, Sugano [47] postulated the mechanism of desaturation of apical transport and negative FE for fenoldopam in the fed state owing to lower luminal drug concentrations. These complex food and drug transport interactions are potentially more common during preclinical studies, where higher doses can likely saturate the apical transporters [48].

Recently, Xiao et al. [49] concluded that higher biliary excretion due to the increased bile flow after food is correlated with negative FE. Although the mechanism can partially explain the negative FE in drugs excreted primarily through bile, there were a few limitations of this hypothesis. First, increased bile flow typically lasts for 1-2 h, whereas biliary excretion of a drug occurs until the entire dose is eliminated from the body [12]. Since the half-life of the majority of the studied drugs is greater than $2 \mathrm{~h}$, it is unlikely that the impact of greater bile flow is clinically significant on biliary excretion. Second, the threshold $(>10 \%)$ used in the study for biliary clearance does not explain a clinically relevant negative FE ( $>25 \%$ decrease). Finally, the biliary excreted fraction was mainly calculated by fecal 
excretion after IV dosing, which can be confounded by intestinal elimination (basolateral uptake and apical efflux).

The interpretation of the impact of prolonged GET in the fed state on drug bioavailability is applicable to explain variability in the drug response in different scenarios, e.g., extended release (ER) formulations and special populations (Figure 6). For example, the saturation of transporter function in the fasted state is likely more common in the immediate release (IR) than in the ER formulation because of the slower release of the drug. Thus in the fed state, although prolonged GET leads to the higher efficiency of transporter function (Figure 5), the effect will be less significant for the ER formulation. An example that supports this hypothesis is gabapentin (L-type amino acid transporter 2, LAT2 substrate), which shows a $42 \%$ higher bioavailability in an ER formulation as compared to its IR formulation following a moderate fat diet [50].

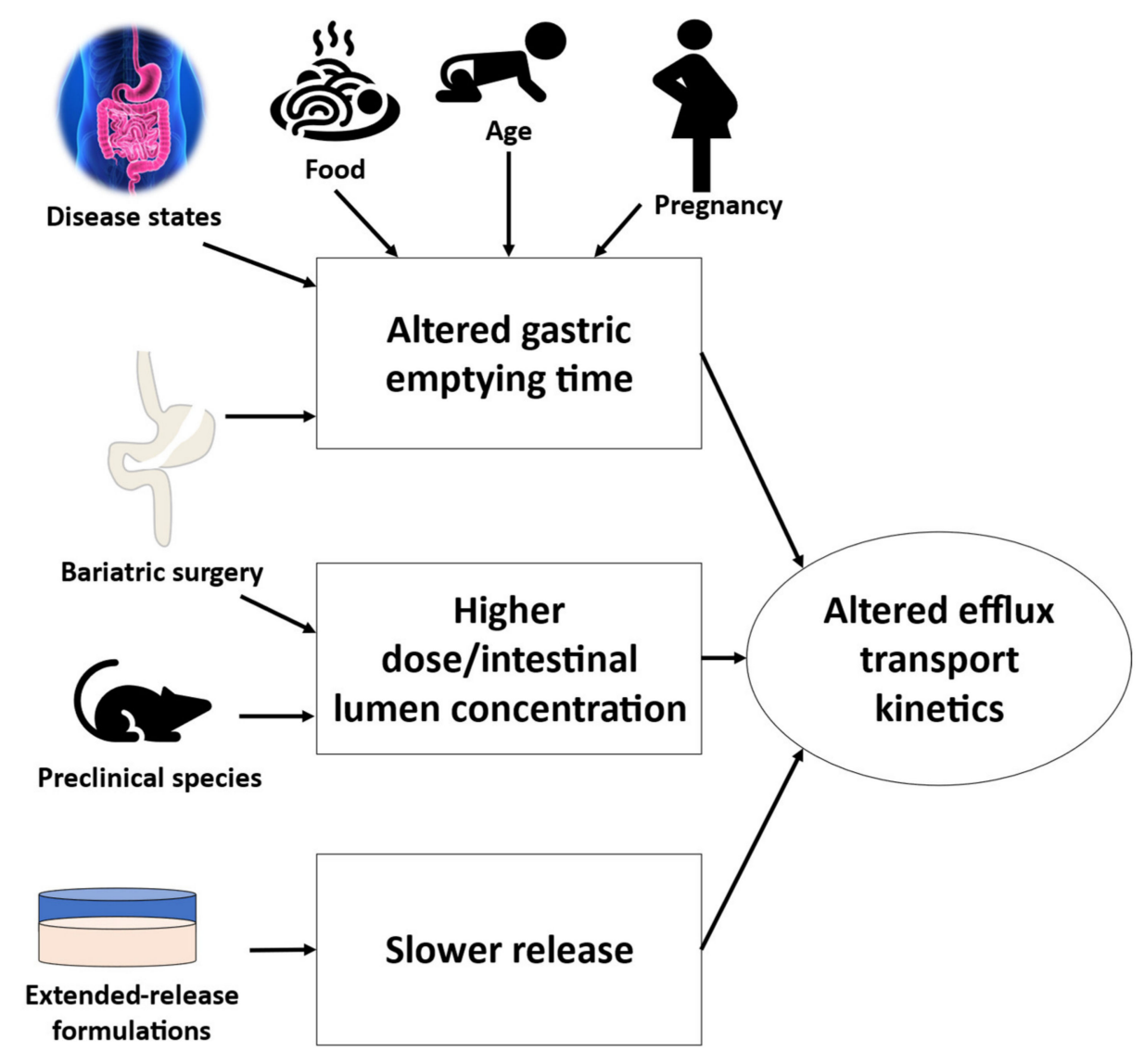

Figure 6. Potential applications of altered gastric emptying time-, higher dose- or intestinal lumen concentration-, and slower drug release-associated changes in efflux transport kinetics. The altered efflux transport kinetics due to the aforementioned factors can be integrated in physiologically based pharmacokinetic (PBPK) modeling of orally absorbed efflux transporter substrate drugs.

Altered GET is also reported in children [51,52], pregnant women [53], and disease states. Drugs with GET-limiting absorption such as paracetamol, digoxin, phenobarbital, and sulfonamides, exhibit a prolonged absorption rate in children [54,55]. The apical uptake and efflux transporters are not fully mature in neonates and infants, but the net efficiency of the transport can be higher in this population due to the prolonged GET, as compared to older children (age > one year) and adults. Similarly, prolonged GET in pregnant women during 8-12 gestational weeks can affect drug absorption and transport efficiency (Figure 5). Pregnancy is associated with multifactorial changes in drug absorption and disposition including prolonged GET that can partially explain the $40 \%$ lower acetaminophen AUC in pregnancy [53]. Further, gastric surgeries and disease states such as ulcerative colitis, 
Crohn's, and coeliac diseases influence gastrointestinal physiology, including the prolongation of GET, which can alter drug bioavailability [56-60]. Therefore, the altered GET due to food, disease, age, bariatric surgery, or pregnancy should be incorporated for reliable physiologically based pharmacokinetic (PBPK) modeling (Figure 6).

The FDA recommends clinical FE studies for investigational drugs and ER dosage forms $[18,19]$. The FE mechanisms such as altered gastric $\mathrm{pH}$, bile secretion, and blood flow are included in the guidance. However, a systematic approach to assess the complex interplay of physiological and physicochemical factors is not provided. Understanding the effect of solubility and transport saturation on oral drug absorption can complement the guidance and provides an a priori outline to design clinical studies by estimating the direction of FE. The proposed mechanisms can be further tested through controlled studies.

There were a few limitations of our study as the present work is dependent on opportunistic FE data, which may be confounded by variations such as diet, co-morbidities, sample size, study population, and technical variability. Moreover, food intake primarily affects the absorption phase of a PK profile but the reported data is based on the net change in the complete AUC profile, including the elimination phase. Next, the analysis cannot test the effect of food on uptake transporter substrate drugs due to fewer drug examples being available. Lastly, the proposed threshold of log dose number and efflux transport saturation index are empirical values. These values for the studied drugs could explain the FE for the drugs under investigation but additional studies are needed to extend these thresholds to other drugs. Furthermore, the results were inconclusive about the differences in the PK endpoints of groups 1 vs. 4 , and 2 vs. 4 . This may be due to the wide range of FE data on $C_{\max }$ and AUC across populations. Nevertheless, our comprehensive analysis of the reported FE studies indicates that the altered interaction between GET and efflux transporters should be integrated into PBPK models to evaluate critical drug absorption parameters in the fed and fasted states.

\section{Conclusions}

This study confirmed that drugs with a higher dose number are prone to positive FE and, if these drugs are not efficiently transported by intestinal transporters, FE can be predicted by in vitro dissolution tests for these drugs. On the other hand, high-affinity efflux transport substrate drugs exhibit a higher likelihood of negative FE that is not predictable by a dissolution test. A typical PK is considered as linear first-order kinetics in the absorption, metabolism, and excretion of drugs. However, we found that the majority of transporter substrate drugs are likely saturated in the fasted state, which is an underappreciated phenomenon. We demonstrated for the first time that the efficiency of drug transporters can be increased for drugs with saturable transport kinetics in the fed state. Such effects of saturable kinetics will be more common in preclinical studies when the oral dose is much higher than the corresponding human dose. The larger magnitude of negative FE in the high-fat diet as compared to the low-fat diet supports our hypothesis. In conclusion, our proposal examines the uncharacterized effect of the interplay between active drug transporters and food on oral drug absorption. This mechanistic understanding, when validated using prospective clinical or preclinical studies, can be used to (i) design optimal FE clinical trials for investigational drugs, (ii) justify biowaivers for FE clinical studies, and (iii) explain inter-species differences in FE due to saturable kinetics.

Supplementary Materials: The following are available online at https:/ / www.mdpi.com/article/10 .3390 / pharmaceutics13071035/s1, Figure S1: P-gp-dependent food-effect due to prolonged gastric emptying time and increased efficiency of P-gp efflux in the fed state. Table S1: Drugs with reported food-effect (FE) studies and their respective physicochemical and biochemical properties.

Author Contributions: Conceptualization, S.S. and B.P.; methodology, S.S. and B.P.; software, S.S. and B.P.; validation, S.S. and B.P.; formal analysis, S.S. and B.P.; investigation, S.S. and B.P.; resources, B.P.; data curation, S.S. and B.P.; writing-original draft preparation, S.S. and B.P.; writing-review 
and editing, S.S. and B.P.; visualization, S.S. and B.P.; supervision, B.P.; project administration, B.P.; funding acquisition, B.P. All authors have read and agreed to the published version of the manuscript.

Funding: The research was supported by Department of Pharmaceutical Sciences, Washington State University, Spokane, WA, and Eunice Kennedy Shriver National Institute of Child Health and Human Development, NIH grant (R01.HD081299).

Institutional Review Board Statement: Not applicable.

Data Availability Statement: Data is contained within the article or Supplementary Materials.

Acknowledgments: The authors would like to express their gratitude to Laken Kruger, Department of Pharmaceutical Sciences, Washington State University, Spokane, WA, for her help with the manuscript editing.

Conflicts of Interest: The authors declare no conflict of interest.

\section{References}

1. Fuentes, A.; Pineda, M.; Venkata, K. Comprehension of Top 200 Prescribed Drugs in the US as a Resource for Pharmacy Teaching, Training and Practice. Pharmacy 2018, 6, 43. [CrossRef]

2. Fleisher, D.; Li, C.; Zhou, Y.; Pao, L.-H.; Karim, A. Drug, Meal and Formulation Interactions Influencing Drug Absorption after Oral Administration. Clin. Pharmacokinet. 1999, 36, 233-254. [CrossRef]

3. Steele, E.L.; Budach, W.; Adamson, P.C.; Pitot, H.C.; Balis, F.M.; Rubin, J.; Murphy, R.F.; Poplack, D.G. Variability in the Oral Bioavailability of All-Trans-Retinoic Acid. Int. J. Cancer 1991, 49, 993-996.

4. Li, M.; Zhao, P.; Pan, Y.; Wagner, C. Predictive Performance of Physiologically Based Pharmacokinetic Models for the Effect of Food on Oral Drug Absorption: Current Status. CPT:PSP 2018, 7, 82-89. [CrossRef]

5. Meng, X.; Mojaverian, P.; Doedée, M.; Lin, E.; Weinryb, I.; Chiang, S.T.; Kowey, P.R. Bioavailability of Amiodarone Tablets Administered with and without Food in Healthy Subjects. Am. J. Cardiol. 2001, 87, 432-435. [CrossRef]

6. Melander, A.; Brante, G.; Johansson, O.; Lindberg, T.; Wahlin-Boll, E. Influence of Food on the Absorption of Phenytoin in Man. Eur. J. Clin. Pharmacol. 1979, 15, 269-274. [CrossRef] [PubMed]

7. Peloquin, C.A.; Namdar, R.; Singleton, M.D.; Nix, D.E. Pharmacokinetics of Rifampin under Fasting Conditions, with Food, and with Antacids. Chest 1999, 115, 12-18. [CrossRef] [PubMed]

8. Bekersky, I.; Dressler, D.; Mekki, Q.A. Effect of Low-and High-Fat Meals on Tacrolimus Absorption Following 5 Mg Single Oral Doses to Healthy Human Subjects. J. Clin. Pharmacol. 2001, 41, 176-182. [CrossRef]

9. Sidery, M.B.; Macdonald, I.A.; Blackshaw, P.E. Superior Mesenteric Artery Blood Flow and Gastric Emptying in Humans and the Differential Effects of High Fat and High Carbohydrate Meals. Gut 1994, 35, 186-190. [CrossRef] [PubMed]

10. Cvijić, S.; Parojčić, J.; Langguth, P. Viscosity-Mediated Negative Food Effect on Oral Absorption of Poorly-Permeable Drugs with an Absorption Window in the Proximal Intestine: In Vitro Experimental Simulation and Computational Verification. Eur. J. Pharm. Sci. 2014, 61, 40-53. [CrossRef]

11. Charman, W.N.; Porter, C.J.H.; Mithani, S.; Dressman, J.B. Physicochemical and Physiological Mechanisms for the Effects of Food on Drug Absorption: The Role of Lipids and PH. J. Pharm. Sci. 1997, 86, 269-282. [CrossRef]

12. Marciani, L.; Cox, E.F.; Hoad, C.L.; Totman, J.J.; Costigan, C.; Singh, G.; Shepherd, V.; Chalkley, L.; Robinson, M.; Ison, R.; et al. Effects of Various Food Ingredients on Gall Bladder Emptying. Eur. J. Clin. Nutr. 2013, 67, 1182-1187. [CrossRef]

13. Abiru, H.; Sarna, S.K.; Condon, R.E. Contractile Mechanisms of Gallbladder Filling and Emptying in Dogs. Gastroenterology 1994, 106, 1652-1661. [CrossRef]

14. Yoshitsugu, R.; Kikuchi, K.; Iwaya, H.; Fujii, N.; Hori, S.; Lee, D.G.; Ishizuka, S. Alteration of Bile Acid Metabolism by a High-Fat Diet Is Associated with Plasma Transaminase Activities and Glucose Intolerance in Rats. J. Nutr. Sci. Vitaminol. 2019, 65, 45-51. [CrossRef]

15. Mclean, A.J.; Mcnamara, P.J.; Dusouich, P.; Gibaldi, M.; Lalka, D.; Buffalo, N.Y. Food, Splanchnic Blood Flow, and Bioavailability of Drugs Subject to First-Pass Metabolism. Clin. Pharmacal. Ther. 1978, 24, 5-10. [CrossRef]

16. Svensson, C.K.; Edwards, D.J.; Mauriello, P.M.; Barde, S.H.; Foster, A.C.; Lanc, R.A.; Middleton, E.; Lalka, D. Effect of Food on Hepatic Blood Flow: Implications in the "Food Effect" Phenomenon. Clin. Pharmacol. Ther. 1983, 34, 316-323. [CrossRef]

17. Harris, R.Z.; Jang, G.R.; Tsunoda, S. Dietary Effects on Drug Metabolism and Transport. Clin. Pharmacokinet. 2003, 42, 1071-1088. [CrossRef] [PubMed]

18. U.S. Department of Health and Human Services, Food and Drug Administration, Center for Drug Evaluation and Research (CDER). Guidance for Industry—Food-Effect Bioavailability and Fed Bioequivalence Studies. Available online: https://www.fda. gov/regulatory-information/search-fda-guidance-documents / food-effect-bioavailability-and-fed-bioequivalence-studies (accessed on 5 August 2020). 
19. U.S. Department of Health and Human Services, Food and Drug Administration, Center for Drug Evaluation and Research (CDER). Guidance for Industry-Assessing the Effects of Food on Drugs in INDs and NDAs. Available online: https:/ / www.fda.gov/regulatory-information/search-fda-guidance-documents/assessing-effects-food-drugs-inds-andndas-clinical-pharmacology-considerations (accessed on 4 August 2020).

20. Zhang, T.; Wells, E. A Review of Current Methods for Food Effect Prediction during Drug Development. Curr. Pharmacol. Rep. 2020, 10, 282-288. [CrossRef]

21. Klein, S. The Use of Biorelevant Dissolution Media to Forecast the in Vivo Performance of a Drug. AAPS J. 2010, 12, 397-406. [CrossRef] [PubMed]

22. Bagchus, W.M.; Hust, R.; Maris, F.; Schnabel, P.G.; Houwing, N.S. Important Effect of Food on the Bioavailability of Oral Testosterone Undecanoate. Pharmacotherapy 2003, 23, 319-325. [CrossRef] [PubMed]

23. Rose, R.H.; Turner, D.B.; Neuhoff, S.; Jamei, M. Incorporation of the Time-Varying Postprandial Increase in Splanchnic Blood Flow into a PBPK Model to Predict the Effect of Food on the Pharmacokinetics of Orally Administered High-Extraction Drugs. AAPS J. 2017, 19, 1205-1217. [CrossRef]

24. Custodio, J.M.; Wu, C.Y.; Benet, L.Z. Predicting Drug Disposition, Absorption/Elimination/Transporter Interplay and the Role of Food on Drug Absorption. Adv. Drug Deliv. Rev. 2008, 60, 717-733. [CrossRef]

25. Ingels, F.; Deferme, S.; Destexhe, E.; Oth, M.; van den Mooter, G.; Augustijns, P. Simulated Intestinal Fluid as Transport Medium in the Caco-2 Cell Culture Model. Int. J. Pharm. 2002, 232, 183-192. [CrossRef]

26. Lown, K.S.; Bailey, D.G.; Fontana, R.J.; Janardan, S.K.; Adair, C.H.; Fortlage, L.A.; Brown, M.B.; Guo, W.; Watkins, P.B. Grapefruit Juice Increases Felodipine Oral Availability in Humans by Decreasing Intestinal CYP3A Protein Expression. J. Clin. Investig. 1997, 99, 2545-2553. [CrossRef]

27. Markowitz, J.S.; Donovan, J.L.; Lindsay Devane, C.; Taylor, R.M.; Ruan, Y.; Wang, J.-S.; Chavin, K.D. Effect of St John's Wort on Drug Metabolism by Induction of Cytochrome P450 3A4 Enzyme. JAMA 2003, 290, 1500-1504. [CrossRef]

28. Schwarz, U.; Seemann, D.; Oertel, R.; Miehlke, S.; Kuhlisch, E.; Fromm, M.; Kim, R.; Bailey, D.; Kirch, W. Grapefruit Juice Ingestion Significantly Reduces Talinolol Bioavailability. Clin. Pharmacol. Ther. 2005, 77, 291-301. [CrossRef]

29. Lennernäs, H.; Regårdh, C.G. Evidence for an Interaction between the Beta-Blocker Pafenolol and Bile Salts in the Intestinal Lumen of the Rat Leading to Dose-Dependent Oral Absorption and Double Peaks in the Plasma Concentration-Time Profile. Pharm. Res. 1993, 10, 879-883. [CrossRef] [PubMed]

30. Dresser, G.; Bailey, D.G.; Leake, B.F.; Schwarz, U.I.; Dawson, P.A.; Freeman, D.J.; Kim, R.B. Fruit Juices Inhibit Organic Anion Transporting Polypeptide-Mediated Drug Uptake to Decrease the Oral Availability of Fexofenadine. Clin. Pharmacol. Ther. 2002, 71, 11-20. [CrossRef] [PubMed]

31. Pao, L.H.; Zhou, S.Y.; Cook, C.; Kararli, T.; Kirchhoff, C.; Truelove, J.; Karim, A.; Fleisher, D. Reduced Systemic Availability of an Antiarrhythmic Drug, Bidisomide, with Meal Co-Administration: Relationship with Region-Dependent Intestinal Absorption. Pharm. Res. 1998, 15, 221-227. [CrossRef]

32. Koziolek, M.; Grimm, M.; Becker, D.; Iordanov, V.; Zou, H.; Shimizu, J.; Wanke, C.; Garbacz, G.; Weitschies, W. Investigation of $\mathrm{PH}$ and Temperature Profiles in the GI Tract of Fasted Human Subjects Using the Intellicap ${ }^{\circledR}$ System. J. Pharm. Sci. 2015, 104, 2855-2863. [CrossRef]

33. Brouwer, K.L.R.; Keppler, D.; Hoffmaster, K.A.; Bow, D.A.J.; Cheng, Y.; Lai, Y.; Palm, J.E.; Stieger, B.; Evers, R. In Vitro Methods to Support Transporter Evaluation in Drug Discovery and Development. Clin. Pharmacol. Ther. 2013, 94, 95-112. [CrossRef]

34. Kosa, R.E.; Lazzaro, S.; Bi, Y.; Tierney, B.; Gates, D.; Modi, S.; Costales, C.; Rodrigues, A.D.; Tremaine, L.M.; Varma, M.V. Simultaneous Assessment of Transporter-Mediated Drug-Drug Interactions Using a Probe Drug Cocktail in Cynomolgus Monkey. Drug Metab. Dispos. 2018, 46, 1179-1189. [CrossRef]

35. Otsuka, K.; Wagner, C.; Selen, A.; Dressman, J. Prediction of In-Vivo Pharmacokinetic Profile for Immediate and Modified Release Oral Dosage Forms of Furosemide Using an in-Vitro-in-Silico-in-Vivo Approach. J. Pharm. Pharmacol. 2015, 67, 651-665. [CrossRef]

36. Hamed, R.; Awadallah, A.; Sunoqrot, S.; Tarawneh, O.; Nazzal, S.; AlBaraghthi, T.; al Sayyad, J.; Abbas, A. PH-Dependent Solubility and Dissolution Behavior of Carvedilol-Case Example of a Weakly Basic BCS Class II Drug. AAPS PharmSciTech 2016, 17, 418-426. [CrossRef]

37. McCrindle, J.L.; Li, T.C.; Wa, K.; Barron, W.; Prescott, L.F. Effect of Food on the Absorption of Frusemide and Bumetanide in Man. Br J. Clin. Pharmacol. 1996, 42, 743-746. [CrossRef] [PubMed]

38. Löbenberg, R.; Amidon, G.L. Modern Bioavailability, Bioequivalence and Biopharmaceutics Classification System. New Scientific Approaches to International Regulatory Standards. Eur. J. Pharm. Biopharm. 2000, 50, 3-12. [CrossRef]

39. Vinarov, Z.; Abdallah, M.; Agundez, J.; Allegaert, K.; Basit, A.W.; Braeckmans, M.; Ceulemans, J.; Corsetti, M.; Griffin, B.; Grimm, M.; et al. Impact of Gastrointestinal Tract Variability on Oral Drug Absorption and Pharmacokinetics: An UNGAP Review. Eur. J. Pharm. Sci. 2021, 162, 105812. [CrossRef]

40. Koziolek, M.; Alcaro, S.; Augustijns, P.; Basit, A.W.; Grimm, M.; Hens, B.; Hoad, C.L.; Jedamzik, P.; Madla, C.M.; Maliepaard, M.; et al. The Mechanisms of Pharmacokinetic Food-Drug Interactions-A Perspective from the UNGAP Group. Eur. J. Pharm. Sci. 2019, 134, 31-59. [CrossRef] 
41. Menssen, H.D.; Quinlan, M.; Kemp, C.; Tian, X. Relative Bioavailability and Food Effect Evaluation for 2 Tablet Formulations of Asciminib in a 2-Arm, Crossover, Randomized, Open-Label Study in Healthy Volunteers. Clin. Pharmacol. Drug Dev. 2019, 8, 385-394. [CrossRef] [PubMed]

42. Damle, B.; Ravandi, F.; Kaul, S.; Sonnichsen, D.; Ferreira, I.; Brooks, D.; Stewart, D.; Alberts, D.; Pazdur, R. Effect of Food on the Oral Bioavailability of UFT and Leucovorin in Cancer Patients. Clin. Cancer Res. 2001, 7, 517-523.

43. Purkins, L.; Wood, N.; Kleinermans, D.; Greenhalgh, K.; Nichols, D. Effect of Food on the Pharmacokinetics of Multiple-Dose Oral Voriconazole. Br. J. Clin. Pharmacol. 2003, 56, 17-23. [CrossRef]

44. Karim, A. Effects of Food on the Bioavailability of Theophylline from Controlled-Release Products in Adults. J. Allergy Clin. Immunol. 1986, 78, 695-703. [CrossRef]

45. Lu, X.; Dong, Y.; Jian, Z.; Li, Q.; Gong, L.; Tang, L.; Zhou, X.; Liu, M. Systematic Investigation of the Effects of Long-Term Administration of a High-Fat Diet on Drug Transporters in the Mouse Liver, Kidney and Intestine. Curr. Drug Metab. 2019, 20, 742-755. [CrossRef]

46. Yamamoto, S.; Kosugi, Y.; Hirabayashi, H.; Moriwaki, T. Impact of P-Glycoprotein on Intestinal Absorption of an Inhibitor of Apoptosis Protein Antagonist in Rats: Mechanisms of Nonlinear Pharmacokinetics and Food Effects. Pharm. Res. 2018, 35, 1-8. [CrossRef]

47. Sugano, K. Chapter 12: Food effect. In Biopharmaceutics Modeling and Simulations Biopharmaceutics Modeling and Simulations: Theory, Practice, Methods, and Applications; John Wiley \& Sons, Inc.: Hoboken, NJ, USA, 2012; pp. 379-411.

48. Daublain, P.; Feng, K.-I.; Altman, M.D.; Martin, I.; Mukherjee, S.; Nofsinger, R.; Northrup, A.B.; Tschirret-Guth, R.; Cartwright, M.; Mcgregor, C. Analyzing the Potential Root Causes of Variability of Pharmacokinetics in Preclinical Species. Mol. Pharm. 2017, 14, 1634-1645. [CrossRef]

49. Xiao, J.; Tran, D.; Zhang, X.; Zhang, T.; Seo, S.; Zhu, H.; Zou, P. Biliary Excretion-Mediated Food Effects and Prediction. AAPS J. 2020, 22, 124. [CrossRef] [PubMed]

50. Swearingen, D.; Aronoff, G.M.; Ciric, S.; Lal, R. Pharmacokinetics of Immediate Release, Extended Release, and Gastric Retentive Gabapentin Formulations in Healthy Adults. Int. J. Clin. Pharm. Ther. 2018, 56, 231-238. [CrossRef] [PubMed]

51. Tayman, C.; Rayyan, M.; Allegaert, K. Neonatal Pharmacology: Extensive Interindividual Variability despite Limited Size. J. Pediatric Pharmacol. Ther. 2011, 16, 170-184. [CrossRef]

52. Batchelor, H. Influence of Food on Paediatric Gastrointestinal Drug Absorption Following Oral Administration: A Review. Children 2015, 2, 244-271. [CrossRef]

53. Levy, D.M.; Williams, O.A.; Magides, A.D.; Reilly, C.S. Gastric Emptying Is Delayed at 8-12 Weeks' Gestation. Br. J. Anaesth. 1994, 73, 237-238. [CrossRef] [PubMed]

54. Nicolas, J.M.; Bouzom, F.; Hugues, C.; Ungell, A.L. Oral Drug Absorption in Pediatrics: The Intestinal Wall, Its Developmental Changes and Current Tools for Predictions. Biopharm. Drug Dispos. 2017, 38, 209-230. [CrossRef]

55. Heimann, G. Enteral Absorption and Bioavailability in Children in Relation to Age. Eur. J. Clin. Pharmacol. 1980, 18, 43-50. [CrossRef] [PubMed]

56. Effinger, A.; O’Driscoll, C.M.; McAllister, M.; Fotaki, N. Impact of Gastrointestinal Disease States on Oral Drug AbsorptionImplications for Formulation Design-a PEARRL Review. J. Pharm. Pharmacol. 2019, 71, 674-698. [CrossRef] [PubMed]

57. Shaffer, J.A.; Williams, S.E.; Turnberg, L.A.; Houston, J.B.; Rowland, M. Absorption of Prednisolone in Patients with Crohn's Disease. Gut 1983, 24, 182-186. [CrossRef]

58. Holt, S.; Heading, R.C.; Clements, J.A.; Tothill, P.; Prescott, L.F. Acetaminophen Absorption and Metabolism in Celiac Disease and Crohn's Disease. Clin. Pharmacol. Ther. 1981, 30, 232-238. [CrossRef] [PubMed]

59. Darwich, A.S.; Henderson, K.; Burgin, A.; Ward, N.; Whittam, J.; Ammori, B.J.; Ashcroft, D.M.; Rostami-Hodjegan, A. Trends in Oral Drug Bioavailability Following Bariatric Surgery: Examining the Variable Extent of Impact on Exposure of Different Drug Classes. Br. J. Clin. Pharmacol. 2012, 74, 774-787. [CrossRef] [PubMed]

60. Nóbrega, A.C.M.; Ferreira, B.R.S.; Oliveira, G.J.; Sales, K.M.O.; Santos, A.A.; Nobre e Souza, M.Â.; Braga, L.L.B.C.; de Almeida Troncon, L.A.E.; Souza, M.H.L.P. Dyspeptic Symptoms and Delayed Gastric Emptying of Solids in Patients with Inactive Crohn's Disease. BMC Gastroenterol. 2012, 12, 1-6. [CrossRef] 